\title{
Adenocarcinoma of the caecum metastatic to the bladder: an unusual cause of haematuria Benjamin R Grey ${ }^{1}$, Laurence Clarke*1, Satish B Maddineni ${ }^{1}$, Roger Hunt ${ }^{2}$ and Richard J Brough ${ }^{1}$
}

Address: ${ }^{1}$ Department of Urology, Stepping Hill Hospital, Stockport, UK and 2Department of Histopathology, Stepping Hill Hospital, Stockport, UK

Email: Benjamin R Grey - bengrey@doctors.org.uk; Laurence Clarke* - lclarke@ doctors.org.uk; Satish B Maddineni - satishandsian@yahoo.co.uk; Roger Hunt - Roger.Hunt@stockport-tr.nwest.nhs.uk; Richard J Brough - r.brough@ntlworld.com

* Corresponding author

Published: 14 October 2006

BMC Urology 2006, 6:29 doi:10.1 I86/147|-2490-6-29
Received: 21 May 2006

Accepted: 14 October 2006

This article is available from: http://www.biomedcentral.com/I47I-2490/6/29

(c) 2006 Grey et al; licensee BioMed Central Ltd.

This is an Open Access article distributed under the terms of the Creative Commons Attribution License (http://creativecommons.org/licenses/by/2.0), which permits unrestricted use, distribution, and reproduction in any medium, provided the original work is properly cited.

\begin{abstract}
Background: Primary malignancies of colorectal origin can metastasise to the bladder. Reports are however extremely rare, particularly from the caecum.

Case report: The report describes the case of a 45-year old male with Duke's B caecal carcinoma treated with a laparoscopically-assisted right hemicolectomy and adjuvant 5-Fluorouracil chemotherapy. Subsequently, a metastatic lesion to the bladder was demonstrated and successfully excised by partial cystectomy.

Conclusion: In order that optimal therapeutic options can be determined, it is important for clinicians to distinguish between primary disease of the bladder and other causes of haematuria. Various immunohistochemical techniques attempt to differentiate primary adenocarcinoma of the bladder from secondary colorectal adenocarcinoma. Suspicion of metastatic disease must be raised when histologically unusual bladder tumours are identified.
\end{abstract}

\section{Background}

The vast majority of bladder tumours are primary transitional cell carcinomas. Primary adenocarcinomas of the bladder are rarer but well recognized. Secondary neoplastic growths of the bladder account for approximately $2 \%$ of bladder malignancies [1]. Bladder involvement in patients with primary colorectal adenocarcinomas is most likely to be secondary to direct invasion from the adjacent recto-sigmoid. Isolated distant metastases to the bladder from colorectal primary disease have very rarely been reported [2-5]. This case presents a case of frank haematuria related to a bladder metastasis from a mucinous adenocarcinoma of the caecum.

\section{Case presentation}

A 45-year-old man presented with vague abdominal pain associated with a palpable mass. An ultrasound scan demonstrated a mass in the right iliac fossa but no evidence of hepatic metastases or lymphadenopathy. A plain X-ray film of the chest demonstrated no abnormality. A subsequent barium enema suggested a caecal carcinoma and he was subsequently treated for a pT3 NO MO (Dukes B) moderately differentiated mucinous adenocarcinoma of the caecum in July 2002 with a laparoscopically-assisted right hemicolectomy. A complete oncological resection was achieved with clear surgical resection margins of at least 4 centimetres. Fourteen lymph nodes were sampled 
but no metastatic disease was identified. In concordance with his high risk for microsatellite instability, he underwent 30 sessions of weekly adjuvant 5-Fluorouracil (5FU) chemotherapy with minimal co-morbidity. Eight months post-operatively he was referred to the Urology Department with a 4-month history of irritative lower urinary tract symptoms that had culminated with a short history of frank haematuria.

An initial flexible cystoscopy revealed a solid-looking 2 $\mathrm{cm}$ growth on the posterior bladder wall. A subsequent intravenous urogram demonstrated normal upper tracts. He underwent trans-urethral resection of the bladder tumour (TURBT) through to deep muscle. Histology of the TURBT specimen revealed a moderately differentiated adenocarcinoma with the following immunoprofile: CK20 and CDX2 +ve, but CK7 -ve. This tissue contained no evidence of extensive cystitis cystica glandularis, intes- tinal metaplasia or any in-situ component, as may be seen in a primary bladder adenocarcinoma. Comparison was made with the original caecal pathology. Morphologically and immunohistochemically these specimens were identical, suggesting bladder metastases from the primary caecal malignancy (Figure 1). A computed tomography (CT) scan at this time revealed no sign of further metastatic disease. The Oncology Department arranged for him to receive CT-staged 3-D conformal multi-fractionated radiotherapy to a total dose of 56 Gray (Gy).

Ten months following the original TURBT, recurrent bladder tumour was found in the same position at check cystoscopy. This was confirmed to be recurrent moderately differentiated intestinal-type adenocarcinoma. Magnetic Resonance scanning revealed a mass involving the right antero-lateral bladder wall and dome extending to the perivesical fat and the right vas deferens. Review of the

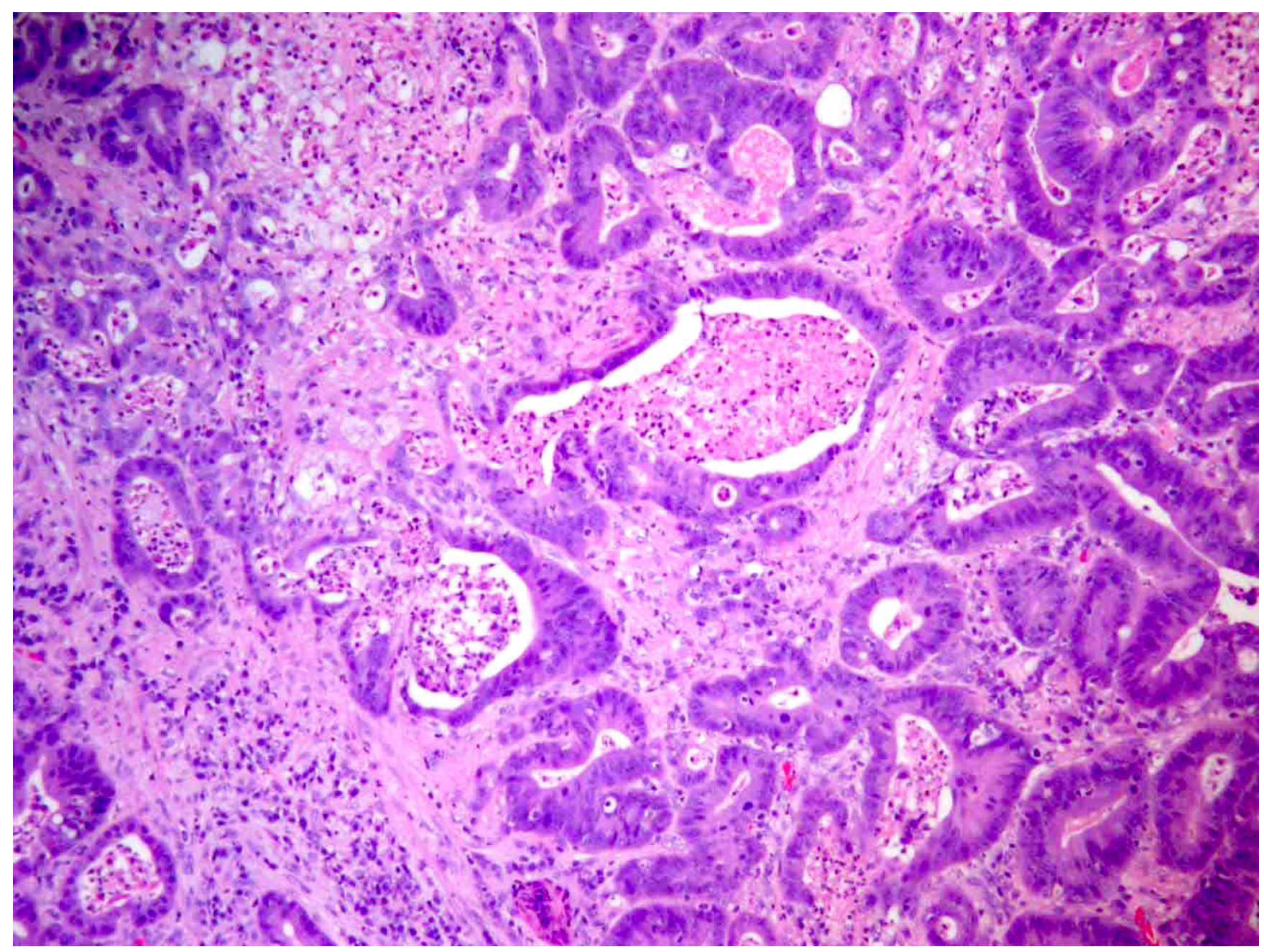

Figure I

Moderately differentiated adenocarcinoma with extensive luminal necrosis. 
scans at the Uroradiology multidisciplinary team meeting suggested the lesion to actually be stage pT2b with associated post-TURBT perivesical inflammatory changes. There was no evidence of lymphadenopathy or metastatic disease. Furthermore neither recurrent colon tumour nor any direct involvement between bowel and bladder were identified. Subsequently he was offered and underwent a partial cystectomy (Figures 2 and 3). There was no evidence of recurrent disease at twelve-month review.

\section{Discussion}

Distant metastases to the bladder have been reported in patients with primary stomach $[2,6]$, skin $[2,7,8]$, breast [2,9-11], lung [2], pancreatic [2,12], uterine [2,13] and oesophageal malignancies [14]. Caecal primaries are anatomically less likely to invade the bladder than neoplasms of the rectosigmoid. This rare case provides evidence consistent with distant metastases to the bladder which were subsequently treated surgically with clear resection margins (Figure 3).

A correct distinction between primary adenocarcinoma of the bladder and secondary colorectal adenocarcinoma is important for staging of disease, determining appropriate treatment and ultimate prognosis [15]. In this case, the patient had already received treatment for a caecal tumour. If however the bladder metastasis was the presenting feature, it would be important to identify and evaluate the underlying primary in the colorectum. Immunohistochemical similarities between primary adenocarcinoma and secondary colorectal adenocarcinoma of the bladder however make this task difficult $[15,16]$.

As in this case, immunostains CK7 and CK20 are commonly used to aid diagnosis, with most lesions of colorectal origin having a CK7 negative and CK20 positive profile

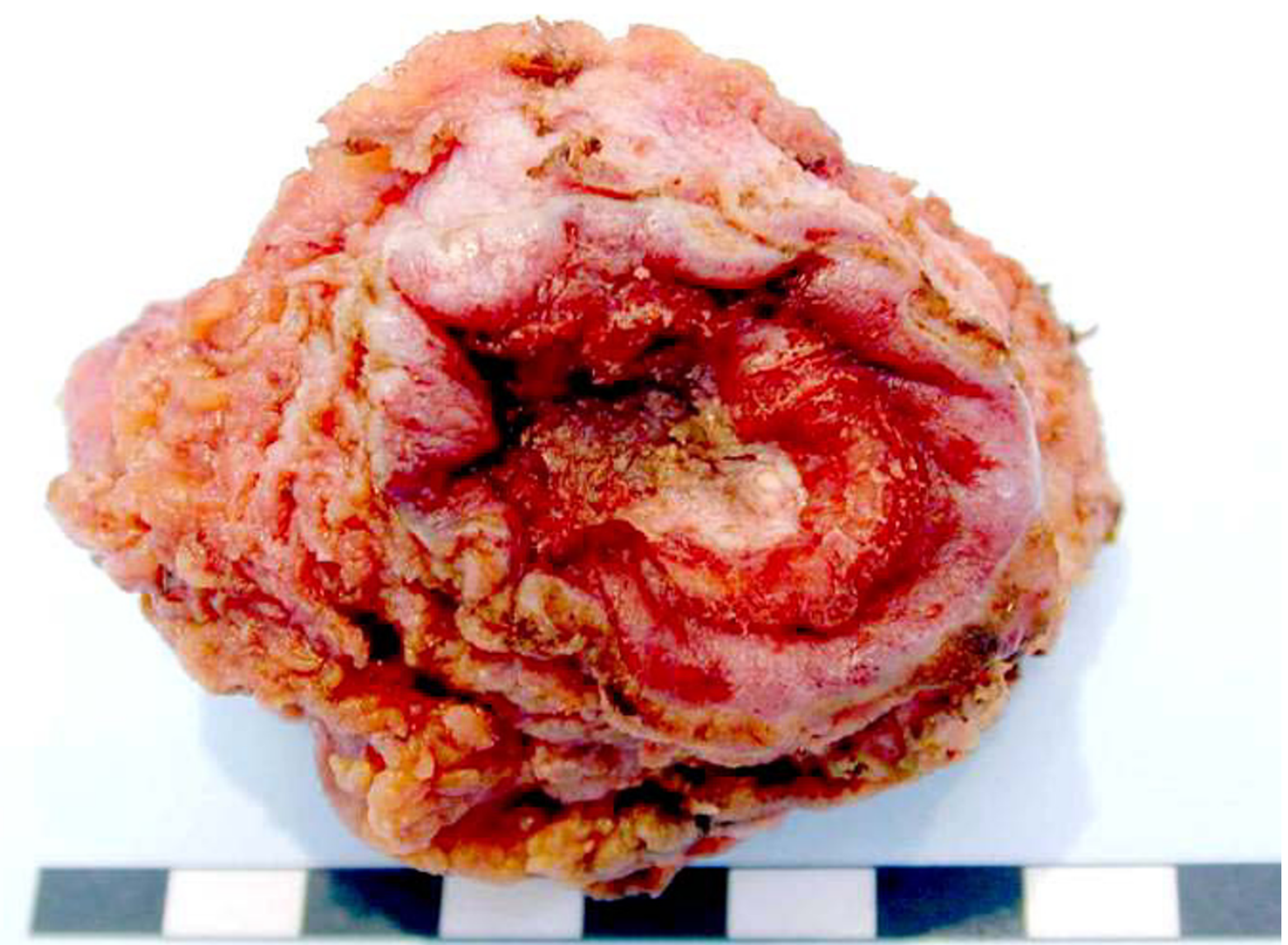

\section{Figure 2}

Luminal surface of partial cystectomy specimen with deposit of metastatic carcinoma. 


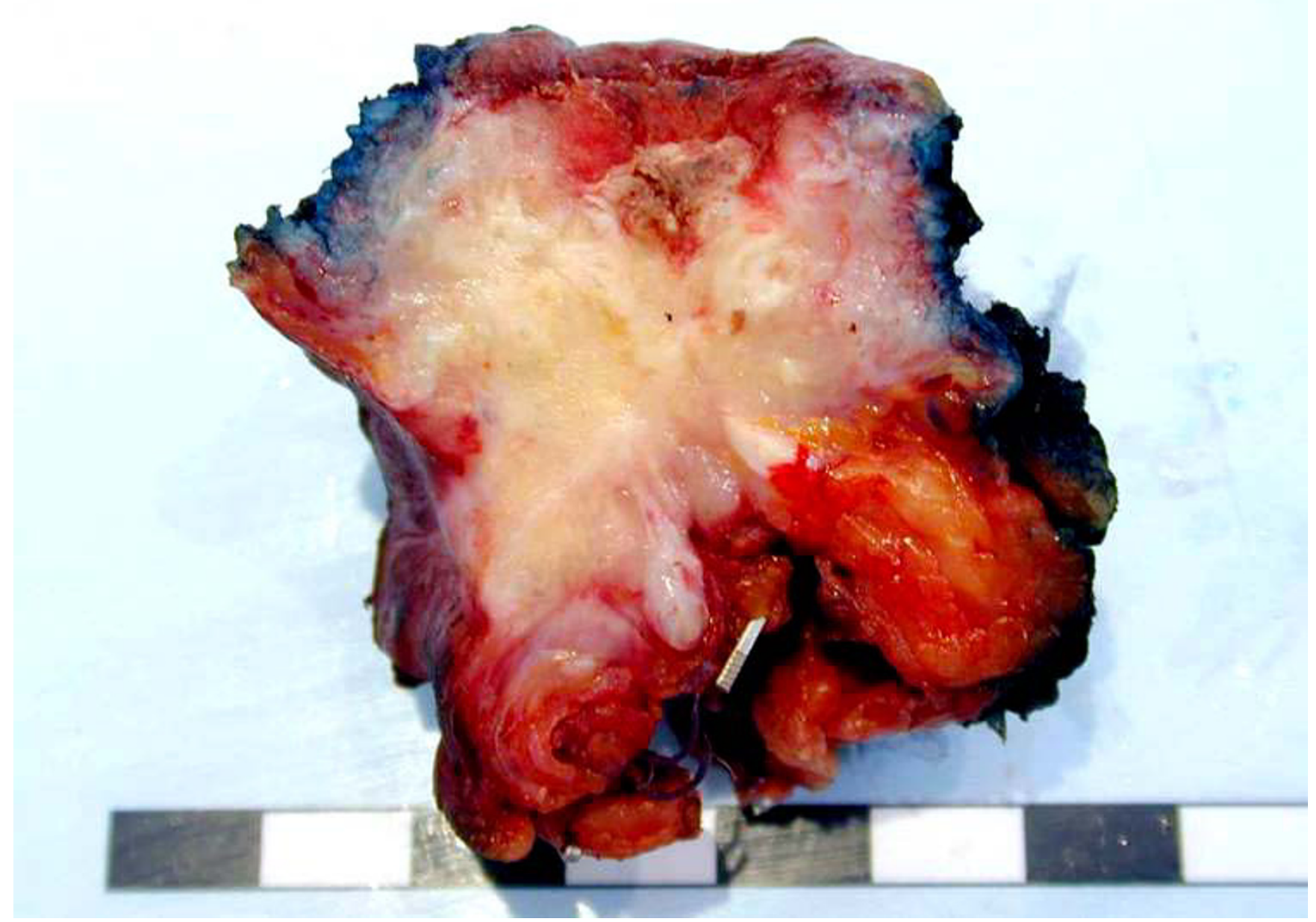

\section{Figure 3}

Sagittal slice of partial cystectomy specimen revealing superficial carcinoma.

(Figure 4). The study by Wang et al. in 2001 reinforced previously published results [17], suggesting stains for CK7 and CK20 were positive in greater than one half of primary bladder adenocarcinoma tissue samples. The authors however concluded that combined staining for CK7 and CK20 alone did not provide sufficient specificity for accurate differentiation between the two clinical scenarios. The investigators discussed the failure of the tumour suppressor adenomatous polyposis coli (APC) gene in colorectal tumorigenesis and the consequent rise in the cell degradation product $\beta$-catenin. Nuclear staining of metastatic colonic carcinoma with $\beta$-catenin aids in distinguishing primary from metastatic adenocarcinomas with nuclear positivity in $81 \%$ of metastatic tumours compared to less than $1 \%$ of primary carcinomas [15]. The study by Wang et al. also suggested that thrombomodulin expression as a marker of primary bladder carcinoma adds to the specificity of the CK7 and CK20 profile. 59\% of pri- mary bladder adenocarcinomas demonstrated significant expression of membranous thrombomodulin compared to $0 \%$ of colonic adenocarcinomas [15]. CDX2 is a homeobox transcription factor that regulates the differentiation of intestinal epithelial cells. As in this case, it has been shown to be of diagnostic use in aiding distinction between primary adenocarcinoma of the bladder and secondary colorectal carcinoma [18]. Tamboli et al. also suggested the use of stains for Villin and concluded that their use, in addition to CK7 and CK20, allowed urothelial carcinoma with glandular differentiation to be distinguished from secondary colonic carcinoma [19]. The available evidence suggests that an immunohistochemical panel of CK7, CK20, CDX2, beta-catenin, thrombomodulin and Villin may best distinguish primary bladder adenocarcinomas from metastases. However, it should be noted that in total the current literature contains relatively few cases of primary bladder adenocarcinoma that have been eval- 


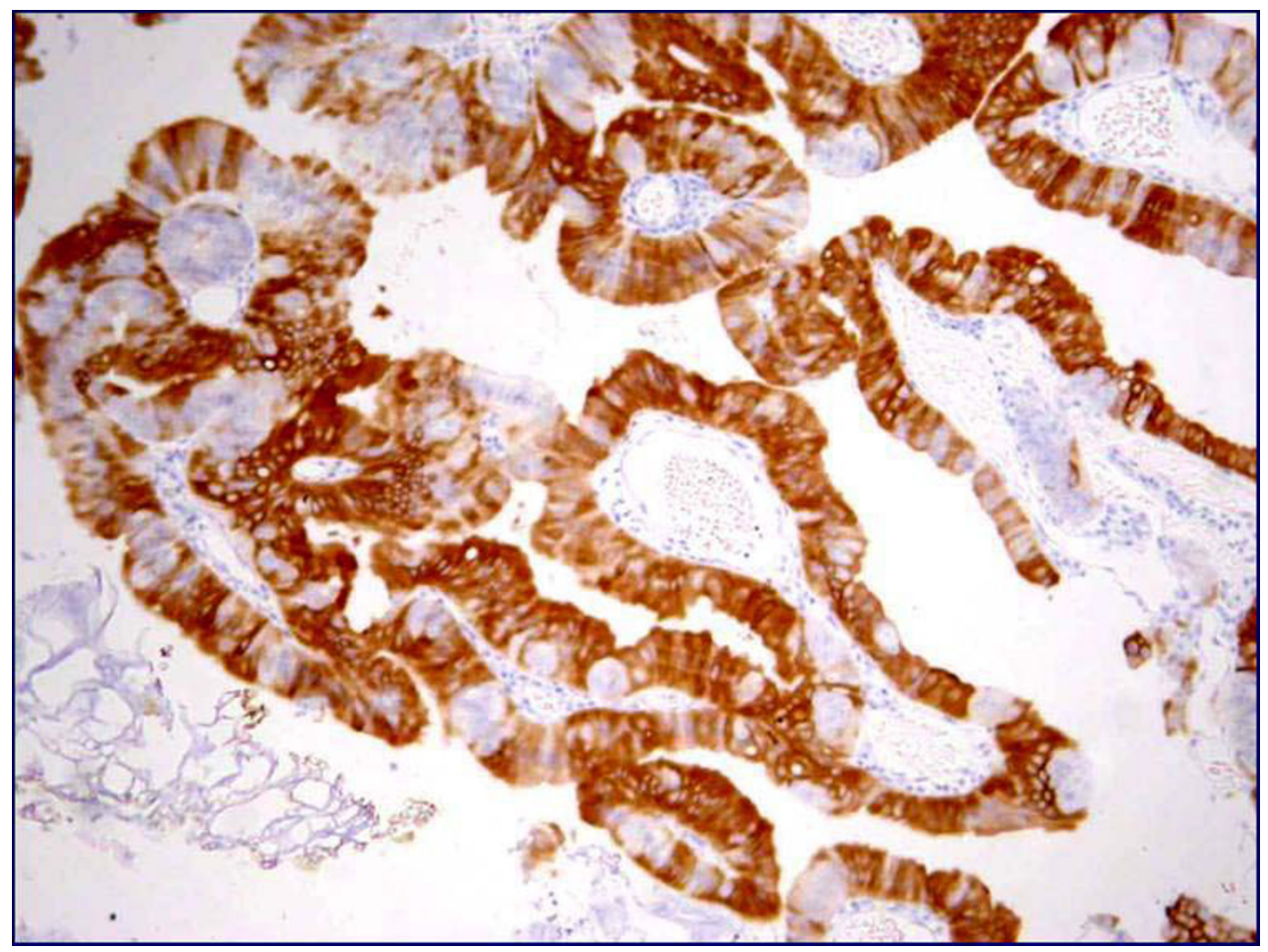

Figure 4

Strong cytoplasmic and membranous CK20 positivity in metastatic colorectal carcinoma.

uated immunohistochemically and further work in this field is needed before a definitive panel that enables discrimination between primary and metastatic bladder adenocarcinomas can be established.

\section{Conclusion}

This case highlights the rare complication of a distant bladder metastasis from a caecal carcinoma. This was successfully treated with a surgical resection and the patient had not suffered recurrence after twelve months of followup. Suspicion of metastatic disease must be considered when histologically unusual bladder tumours are identified. In the absence of pre-existing malignant disease immunohistochemical panels of antibodies are often required to try and identify the focus of primary disease thus allowing appropriate treatment regimen to be formulated.

\section{Abbreviations}

TURBT: Transurethral resection of bladder tumour

\section{Competing interests}

The author(s) declare that they have no competing interests.

\section{Authors' contributions}

RJB was the lead clinician responsible for the patient's care, performed the partial cystectomy and along with SBM and RH conceived the idea for the report. RH carried out the pathological and immunohistochemical analysis of the specimens. Furthermore, $\mathrm{RH}$ provided appraisal of the pathological discussion. BRG, LC and SBM were also members of the surgical team, reviewed the case notes and drafted the manuscript. All authors read, appraised and approved the final manuscript.

\section{Acknowledgements}

Written consent was obtained from the patient prior to publication of this case report.

\section{References}

I. Bates AW, Baithun SI: Secondary neoplasms of the bladder are histological mimics of non-transitional cell primary tumours: Clinico-pathological and histological features of 282 cases. Histopathology 2000, 36:32-40.

2. Ganem EJ, Batal JT: Secondary malignant tumors of the urinary bladder metastatic from primary foci in distant organs. The Journal of Urology 1956, 75:965-972.

3. Hobdy EM, Cielsielski TE, Kummar S: Unusual sites of colorectal cancer metastasis. Clin Colorectal Cancer 2003, 3( I):54-57.

4. Vyslouzil K, Klementa I, Cwiertka K, Herman M, Konecny M: Less common metastases of colorectal adenocarcinoma. Rozhl Chir 1997, 76( I 2):6| 9-62I.

5. Saba NF, Hoenig DM, Cohen SI: Metastatic signet-ring cell adenocarcinoma to the urinary bladder. Acta Oncologica 1997, 36(2):219-220. 
6. Van Driel MF, Ypma AF, Van Gelder B: Gastric carcinoma metastatic to the bladder. Br J Urol 1987, 59(2): 193-194.

7. Fink W, Zimpfer A, Ugurel S: Mucosal metastases in malignant melanoma. Onkologie 2003, 26:249-25I.

8. Menendez Lopez V, Alvarez-Vijande Garcia R, Sole Arques M, Carretero Gonzalez P: Bladder metastasis of malignant melanoma: Report of a case. Arch Esp Urol 2002, 55:I277-I 279.

9. Feldman PA, Madeb R, Naroditsky I, Halachmi S, Nativ O: Metastatic breast cancer to the bladder: $A$ diagnostic challenge and review of the literature. Urology 2002, 59(I): 138.

10. Poulakis V, Witzsch U, de Vries R, Becht E: Metastatic breast carcinoma to the bladder: 5-year follow up. Journal of Urology 200I, 165(3):905.

II. Schneidau T, Stroumbakis N, Choudhury M, Eshgi M, Mallouh C: Metastatic breast cancer to the bladder: A case report. Int Urol Nephrol 1995, 27(3):301-305.

12. Chiang KS, Lamki N, Athey PA: Metastasis to the bladder from pancreatic adenocarcinoma presenting with hematuria. UrolRadiol 1992:187-189.

13. Young RH, Johnston WH: Serous adenocarcinoma of the uterus metastatic to the urinary bladder mimicking primary bladder neoplasia. A report of a case. American Journal of Surgical Pathology 1990, 14(9):877-880.

14. Hargunani R, Al-Dujaily S, Abdulla AKS, Osbourne DR: Haematuria as a presentation of metastatic oesophageal carcinoma. International Seminars in Surgical Oncology 2005, 2:4.

15. Wang HL, Lu DW, Yerian LM, Alsikafi N, Steinberg G, Hart J, Yang $\mathrm{XJ}$ : Immunohistochemical distinction between primary adenocarcinoma of the bladder and secondary colorectal adenocarcinoma. The American Journal of Surgical Pathology 200I, 25(I I): I380-I 387.

16. Silver SA, Epstein Jl: Adenocarcinoma of the colon simulating primary urinary bladder neoplasia. The American Journal of Surgical Pathology 1993, I7(2): I7I-178.

17. Melicow MM: Tumors of the urinary bladder: A clinicopathological analysis of over 2500 specimens and biopsies. Journal of Urology 1955, 74:498-52I.

18. Suh N, Yang XJ, Tretiakova MS, Humphrey PA, Wang HL: Value of CDX2, villin, and alpha-methylacyl coenzyme $A$ racemase immunostains in the distinction between primary adenocarcinoma of the bladder and secondary colorectal adenocarcinoma. Modern Pathology 2005, 18:1217-22.

19. Tamboli P, Mohsin SK, Hailemariam S, Amin MB: Colonic adenocarcinoma metastatic to the urinary tract versus primary tumours of the urinary tract with glandular differentiation. Archives of Pathology and Laboratory Medicine 2002, I 26: 1057- 1063.

\section{Pre-publication history}

The pre-publication history for this paper can be accessed here:

http://www.biomedcentral.com/1471-2490/6/29/prepub

\section{Publish with Bio Med Central and every scientist can read your work free of charge}

"BioMed Central will be the most significant development for disseminating the results of biomedical research in our lifetime. "

Sir Paul Nurse, Cancer Research UK

Your research papers will be:

- available free of charge to the entire biomedical community

- peer reviewed and published immediately upon acceptance

- cited in PubMed and archived on PubMed Central

- yours - you keep the copyright
BioMedcentral 